\title{
Progress of elemental anomalies of hippocampal formation in the pilocarpine model of temporal lobe epilepsy—an X-ray fluorescence microscopy study
}

\author{
J. Chwiej • J. Kutorasinska • K. Janeczko • \\ K. Gzielo-Jurek • L. Uram • K. Appel • R. Simon • \\ Z. Setkowicz
}

Received: 18 July 2012 /Revised: 12 September 2012 / Accepted: 13 September 2012 /Published online: 4 October 2012

(C) The Author(s) 2012. This article is published with open access at Springerlink.com

\begin{abstract}
In the present paper, X-ray fluorescence microscopy was applied to follow the processes occurring in rat hippocampal formation during the post-seizure period. In the study, one of the status epilepticus animal models of epilepsy was used, namely the model of temporal lobe epilepsy with pilocarpine-induced seizures. In order to analyze the dynamics of seizure-induced elemental changes, the samples taken from seizure-experiencing animals $3 \mathrm{~h}$ and 1, 4, and 7 days after proconvulsive agent administration were analyzed. The obtained results confirmed the utility of X-ray fluorescence microscopy in the research of mechanisms involved in the pathogenesis and progress of epilepsy. The topographic and quantitative elemental analysis of hippocampal formations from different periods of epileptogenesis showed that excitotoxicity, mossy fibers sprouting, and iron-induced oxidative stress may be the processes responsible for seizure-induced neurodegenerative changes and spontaneous recurrent
\end{abstract}

\footnotetext{
J. Chwiej $(\bowtie) \cdot J$. Kutorasinska

Faculty of Physics and Applied Computer Science, AGH

University of Science and Technology,

Al. Mickiewicza 30,

30-359 Krakow, Poland

e-mail: Joanna.Chwiej@fis.agh.edu.pl

K. Janeczko $\cdot$ K. Gzielo-Jurek $\cdot$ L. Uram $\cdot$ Z. Setkowicz Institute of Zoology, Jagiellonian University,

Ul. Gronostajowa 9,

30-387 Krakow, Poland

K. Appel

Deutsches Elektronen-Synchrotron (DESY),

Notkestraße 85,

22607 Hamburg, Germany

\section{R. Simon}

Research Centre Karlsruhe, Institut fur Synchrotronstrahlung,

Hermann-von-Helmholtz-Platz 1,

76344 Eggenstein-Leopoldshafen, Germany
}

seizures occurring in the chronic phase of the pilocarpine model. The analysis of correlations between the recorded elemental anomalies and quantitative parameters describing animal behavior in the acute period of pilocarpine-induced status epilepticus showed that the areal densities of selected elements measured in the latent period strongly depend on the progress of the acute phase. Especially important seem to be the observations done for $\mathrm{Ca}$ and $\mathrm{Zn}$ levels which suggest that the intensity of the pathological processes such as excitotoxicity and mossy fibers sprouting depend on the total time of seizure activity. These results as well as dependencies found between the levels of $\mathrm{S}, \mathrm{K}$, and $\mathrm{Cu}$ and the intensity of maximal seizures clearly confirm how important it is to control the duration and intensity of seizures in clinical practice.

Keywords Pilocarpine model of epilepsy · Topographic and quantitative elemental analysis $\cdot \mathrm{X}$-ray fluorescence microscopy $\cdot$ Synchrotron radiation

\section{Introduction}

Intensive development of medicine and biomedical sciences implicates the necessity to search for new investigational tools that would provide more detailed information about biochemical composition of analyzed samples. The unique features of synchrotron radiation, such as high intensity, collimation, and wide spectral range, enable the examination of most subtle biomolecular changes occurring at ranges even less than micrometer [1-6]. Therefore, synchrotron radiation-based techniques such as X-ray crystallography, $\mathrm{X}$-ray fluorescence microscopy, X-ray absorption fine structure spectroscopy, and Fourier transform infrared microspectroscopy play an increasing role in biomedical research [7-14].

Synchrotron radiation-induced X-ray fluorescence microscopy is a very sensitive tool for topographic and quantitative 
multielemental analysis. It offers spatial resolution and detection limits similar to other methods of elemental analysis such as: microparticle-induced X-ray emission, secondary ion mass spectrometry, or electron probe microanalysis [15-17]. However, comparing to them, it usually does not require any special sample preparation and measurement environment [15].

Trace elements are involved in many processes that may finally lead to atrophy and death of nerve cells in case of different central nervous system (CNS) pathologies [18-21]. Therefore, analysis of their tissue levels and distributions may shed some new light on the mechanisms of CNS diseases of unknown or not fully understood etiology. One of them is epilepsy being the third most common neurological disorder after cerebrovascular and Alzheimer's disease. Epilepsy can either be idiopathic or acquired which means that it is initiated by neurological insults including status epilepticus, stroke, or traumatic brain injury. Acquired epilepsy develops in the following three phases: (1) injury, (2) epileptogenesis, and (3) the chronic phase with spontaneous recurrent seizures [22]. Because human tissues for the research of epilepsy can be obtained only postmortem or during surgical resection of epileptic foci, the investigations of the most interesting period of epileptogenesis are carried out based on animal models of the disease. Animal models of epilepsy help to understand better the mechanisms leading to spontaneous seizure activity, allow observations of the progress and character of seizures, as well as evaluation of the action of new antiepileptic drugs [23, 24].

Temporal lobe epilepsy (TLE) is the most frequent and medically refractory epilepsy in humans [25-27]. One of the most frequently used and highly isomorphic with human cases of the TLE animal model is one with seizures induced with pilocarpine [28]. Administration of pilocarpine in rats evokes sequential behavioral and electrographic changes that can be divided into three distinct periods: (1) an acute period that builds up progressively into a limbic status epilepticus, (2) a silent (latent) period with progressive normalization of EEG and behavior, and (3) a chronic period with spontaneous recurrent seizures [29].

In the present paper, we tried to show how X-ray fluorescence microscopy might support the investigation of the mechanisms leading to seizure-induced neurodegenerative changes of hippocampal formation and to spontaneous seizure activity observed in the chronic period of the pilocarpine model. The main purpose of the study was the analysis of the dynamics of the elemental changes observed in rat hippocampus after administration of proconvulsive agent. In order to accomplish it, the topographic and quantitative elemental analysis was carried out on tissues, taken from animals $3 \mathrm{~h}$ (SE3H group) and 1 (SE24H), 4 (SE4D), and 7 (SE7D) days after the pilocarpine injection. Moreover, a correlative analysis was done between recorded elemental anomalies and quantitative parameters describing animal behavior in the acute period of pilocarpine-induced status epilepticus, such as intensity of maximal seizures, latency time after pilocarpine injection, and total time of seizure activity within the observation period.

\section{Materials and methods}

All animal experimental procedures were accepted by the Bioethical Commission of Jagiellonian University and were in agreement with the international standards. Adult Wistar rats were obtained from an animal colony of the Department of Neuroanatomy, Institute of Zoology, Jagiellonian University, Krakow. During their whole life, the animals were maintained under conditions of controlled temperature (20 $\left.\pm 2{ }^{\circ} \mathrm{C}\right)$ and illumination (12:12-h light/dark cycle). A solid diet (Labofeed) and water were available ad libitum.

Seizures were induced in 60-day-old male Wistar rats by i.p. injection of pilocarpine $(300 \mathrm{mg} / \mathrm{kg}$; Sigma P6503). Scopolamine methyl bromide (1 mg/kg; Sigma S8502) was injected i.p. $30 \mathrm{~min}$ before pilocarpine to reduce its peripheral effects.

The animals were deeply anesthetized using Vetbutal (Polfa) and perfused with $0.9 \%$ saline of high analytical grade $3 \mathrm{~h}$ and 1, 4, and 7 days after pilocarpine administration. The brains removed from the skull were first deeply frozen in liquid nitrogen and then cut horizontally in a cryomicrotome into $15-\mu \mathrm{m}$-thick sections. The specimens of the dorsal part of the hippocampus [30] were mounted on Ultralene ${ }^{\circledR}$ foil and freeze dried. The numbers of animals representing the analyzed animal groups are specified in Table 1.

\section{Experimental method and apparatus}

X-ray fluorescence microscopy was used for the qualitative, quantitative, and topographic elemental analysis. The measurements were carried out at HASYLAB beamline $\mathrm{L}$ and the FLUO beamline at ANKA. In both cases, excitation energy of $17 \mathrm{keV}$ was selected and the X-ray beam was focused

Table 1 Experimental groups

\begin{tabular}{lccc}
\hline Group & Pilocarpine injection & Sampling time $^{\mathrm{a}}$ & Quantity \\
\hline $\mathrm{N}$ & & $3 \mathrm{~h}$ & 5 \\
$\mathrm{SE} 3 \mathrm{H}$ & + & $3 \mathrm{~h}$ & 4 \\
$\mathrm{SE} 24 \mathrm{H}$ & + & $24 \mathrm{~h}$ & 5 \\
SE4D & + & 4 days & 5 \\
SE7D & + & 7 days & 16 \\
\hline
\end{tabular}

$N$ naive rats

${ }^{a}$ Time of perfusion with physiological saline solution calculated from pilocarpine injection 
with polycapillary optics. The diameter of the beam impinging on the sample was 15 and $12 \mu \mathrm{m}$, respectively. Silicon drift detectors were used to detect the fluorescence radiation from the sample. The detectors were positioned at the angle of $45^{\circ}$ in respect to sample and $90^{\circ}$ in respect to the exciting beam. The samples were mapped in two dimensions and the time of single fluorescence spectrum acquisition was $10 \mathrm{~s}$ at beamline $\mathrm{L}$ and $8 \mathrm{~s}$ at the FLUO beamline.

Reference measurements on the following MICROMATTER XRF calibration standards: $\mathrm{GaP}, \mathrm{KCl}, \mathrm{CaF}_{2}, \mathrm{Fe}, \mathrm{ZnTe}$, $\mathrm{Se}$, and $\mathrm{RbI}$ were performed for spectrometer calibration and elemental sensitivities calculations.

\section{Results}

The applied measurement conditions allowed to detect elements with atomic numbers between 15 and 38 in the nervous tissue as demonstrated in Fig. 1 which shows the cumulative spectrum of the hippocampal formation.

The analysis of single X-ray fluorescence spectra as well as batch processing of large datasets were carried out using PyMCA software freely available for noncommercial use. The obtained net peak areas of K- $\alpha$ lines of the analyzed elements and the elemental sensitivities evaluated based on the measurements of calibration standards allowed to calculate elemental areal densities for the examined tissue points. Details of the quantitative analysis were presented elsewhere [31]. The comparisons between the examined animal groups were done only for these elements that for all the used experimental conditions, analyzed samples, and measured areas presented the areal densities higher than the detection limits calculated for the tissue samples. Additionally, from further analysis we excluded $\mathrm{Cl}$ which originated mainly from physiological saline solution used for perfusion of animals and $\mathrm{Pb}$ which was mainly of apparatus origin. Finally, the contents of $\mathrm{S}, \mathrm{K}, \mathrm{Ca}, \mathrm{Fe}, \mathrm{Cu}$, and $\mathrm{Zn}$ were analyzed in frame of the study.

The next step of the work was the topographic analysis of the examined samples. In Figs. 2 and 3, the results of such analysis done for selected SE7D and control samples are presented.

The comparison of elemental maps with the microscopic views of the scanned tissues allowed identifying the hippocampal areas for further comparison between analyzed animal groups. These were sectors 1 and 3 of the Ammon's horn (CA1 and CA3, respectively), the dentate gyrus (DG) and hilus of DG $(\mathrm{H})$. For all examined samples, the mean elemental areal densities in the abovementioned areas were calculated. In order to analyze the statistical significance of the differences between animals from different periods of epileptogenesis, the medians of mean values were evaluated for SE3H, SE24H, SE4D, and SE7D groups, as well as naive rats and the obtained results are presented in Fig. 4.

For statistical analysis of the obtained results, nonparametric tests were applied. Such a choice was dictated primarily by the sizes of the experimental groups, which were too little to verify the normality of data distributions. The Mann-Whitney $U$ test was applied for statistical evaluation of the differences between animal populations under analysis. In turn, statistically significant dependencies between elemental anomalies and parameters describing animal behavior in the acute phase of pilocarpine-induced status epilepticus were determined based on the values of Spearman's rank correlation coefficients.

Evaluation of the elements presenting statistically significant differences in accumulation between analyzed groups was done based on $p$ values of the $U$ test at the significance
Fig. 1 Cumulative spectrum recorded for the hippocampal formation from rat representing SE7D group

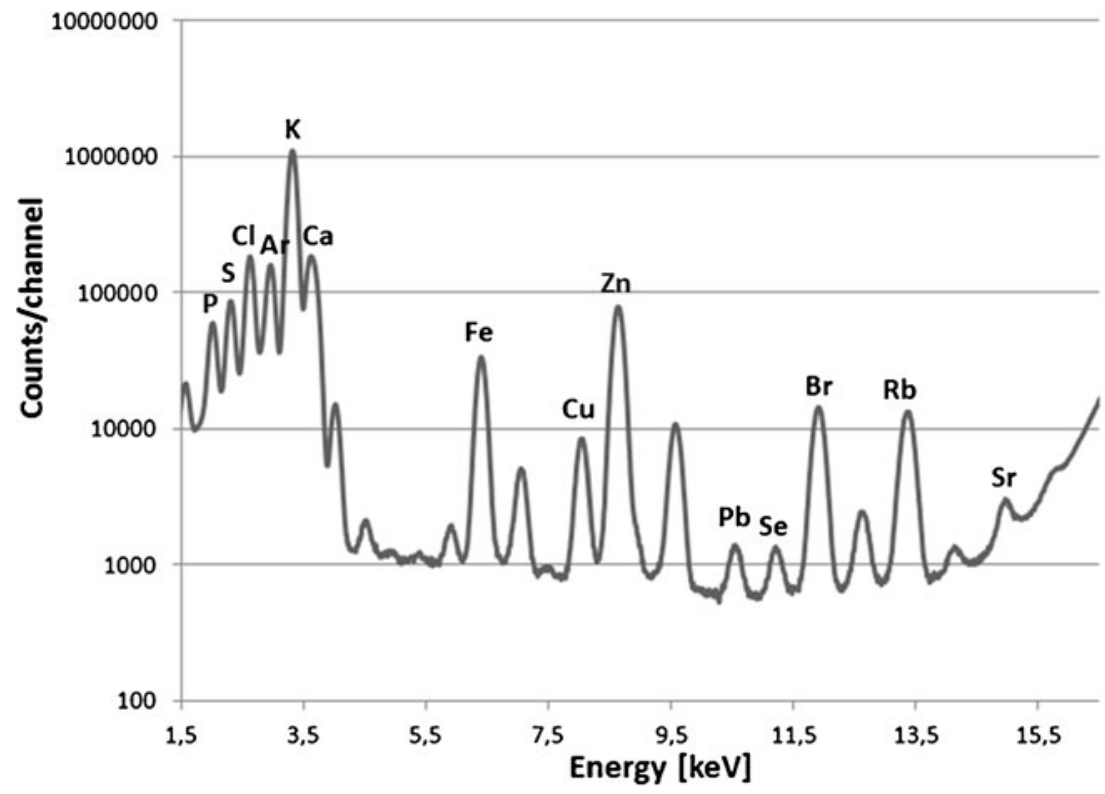



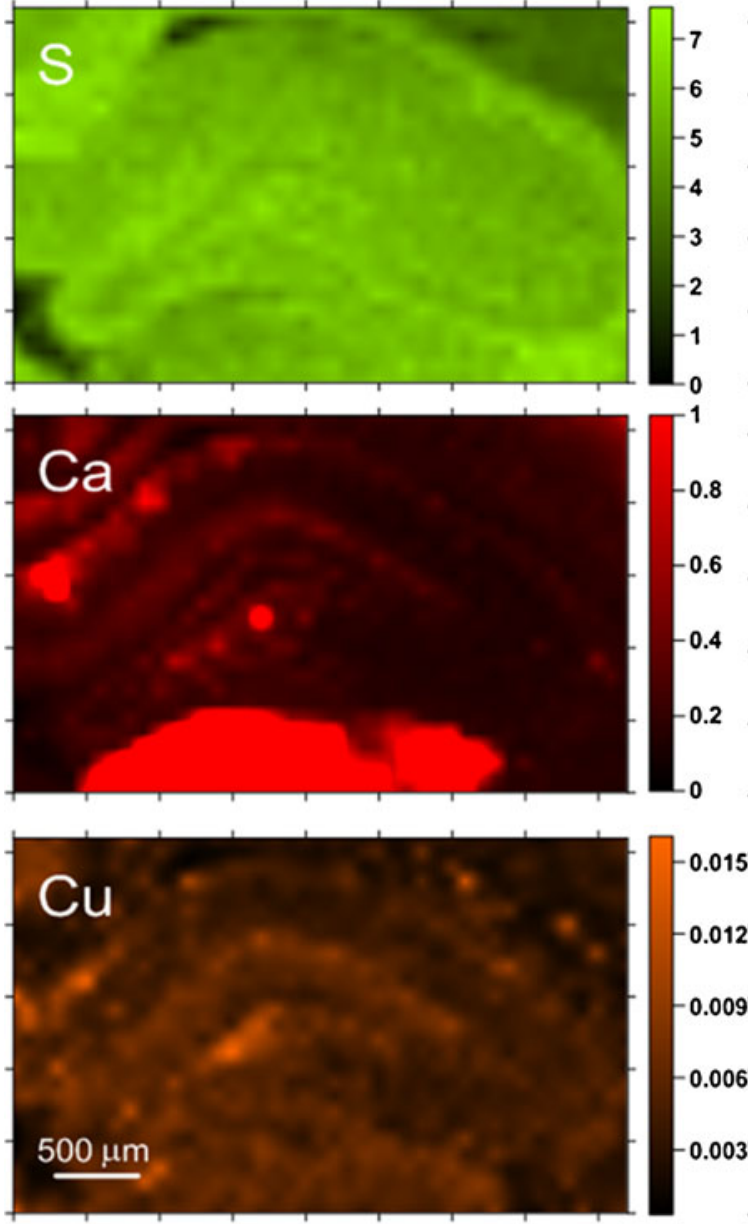

Fig. 2 Elemental maps obtained for hippocampal tissue from a selected SE7D epileptic animal. Scales display masses per unit area of the elements in micrograms per square centimeter

level of 0.05 and the obtained results are shown in Table 2 and schematically pictured in Fig. 5.

As one can see in Fig. 5, the level of S does not change in any of the examined areas during the first $3 \mathrm{~h}$ after pilocarpine administration. During the next observation period, the areal density of this element decreases in the CA3 sector while between the first and fourth day of the observation, it increases in the CA3 and DG hippocampal areas. In the next examined time period, the level of S does not change, and on the seventh day from the injection of pilocarpine, the areal density of $\mathrm{S}$ reaches the value of the control group. Thus, fluctuations of the S content in the analyzed hippocampal areas seem to be temporary effect of pilocarpineinduced seizures.

In all hippocampal areas, despite DG, the content of $\mathrm{Ca}$ increases significantly already $3 \mathrm{~h}$ after pilocarpine administration. In DG, this rise appears with delay, between the third and twenty-fourth hour, when in the other examined areas the level of $\mathrm{Ca}$ decreases (CA1 and CA3) or remains constant $(\mathrm{H})$. In the next time period, the areal density of $\mathrm{Ca}$ increases again in $\mathrm{CA} 3, \mathrm{DG}$, and $\mathrm{H}$ hippocampal areas and
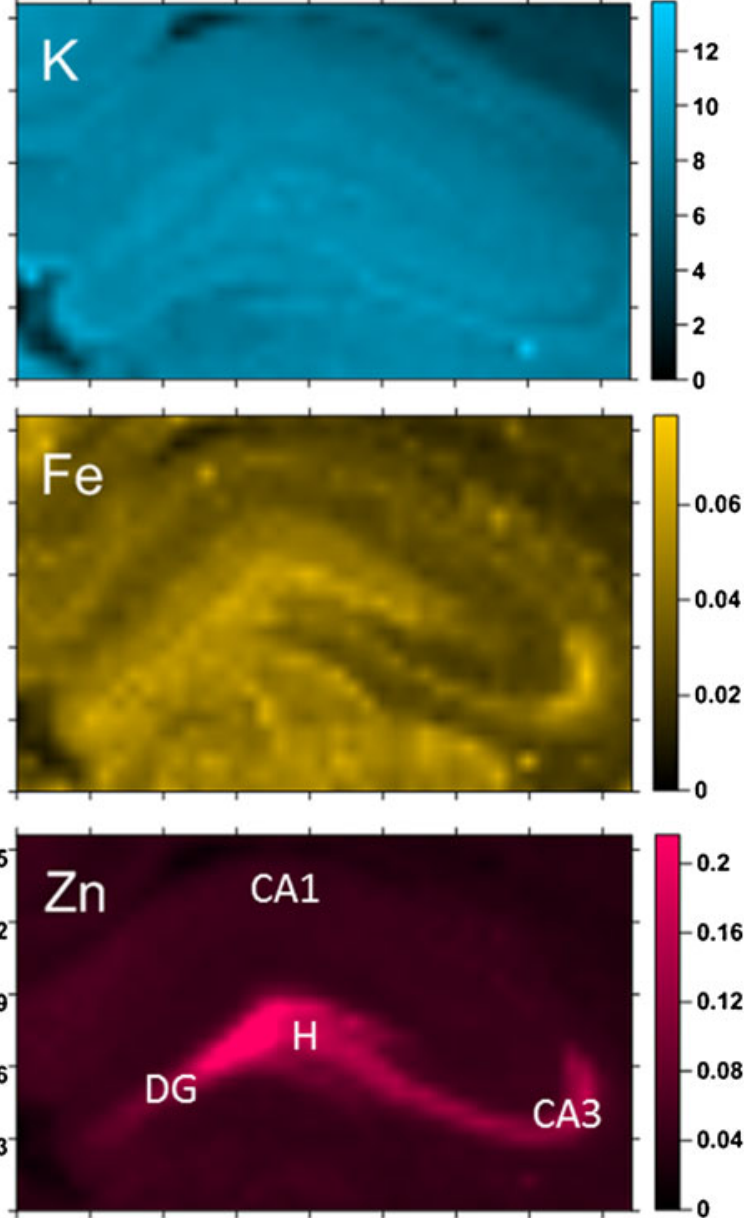

afterwards remains at a constant level which for all of the analyzed areas is at least twice higher than that recorded for the control group.

Iron areal density decreases during the first $3 \mathrm{~h}$ from pilocarpine administration in DG and during the next $21 \mathrm{~h}$ of the acute phase in CA1 hippocampal area. Afterwards, during the whole latent period (between the twenty-fourth hour and seventh day from pilocarpine injection), the level of Fe increases in CA3, DG, and $\mathrm{H}$, while for hilus of DG these changes are not statistically significant. Seven days after pilocarpine administration, the content of $\mathrm{Fe}$ for these three areas remains higher than the level recorded in control samples.

Accumulation of $\mathrm{Zn}$ does not change during the first $3 \mathrm{~h}$ from pilocarpine injection in any of the examined hippocampal areas. During the next $21 \mathrm{~h}$ of the acute phase, the $\mathrm{Zn}$ level starts to increase in $\mathrm{H}$ and this tendency persists throughout the remaining 6 days of the observation period. During the first 3 days of the latent phase, the increase in $\mathrm{Zn}$ level includes also DG and CA3 hippocampal areas. Seven days after pilocarpine administration, the areal density of $\mathrm{Zn}$ 

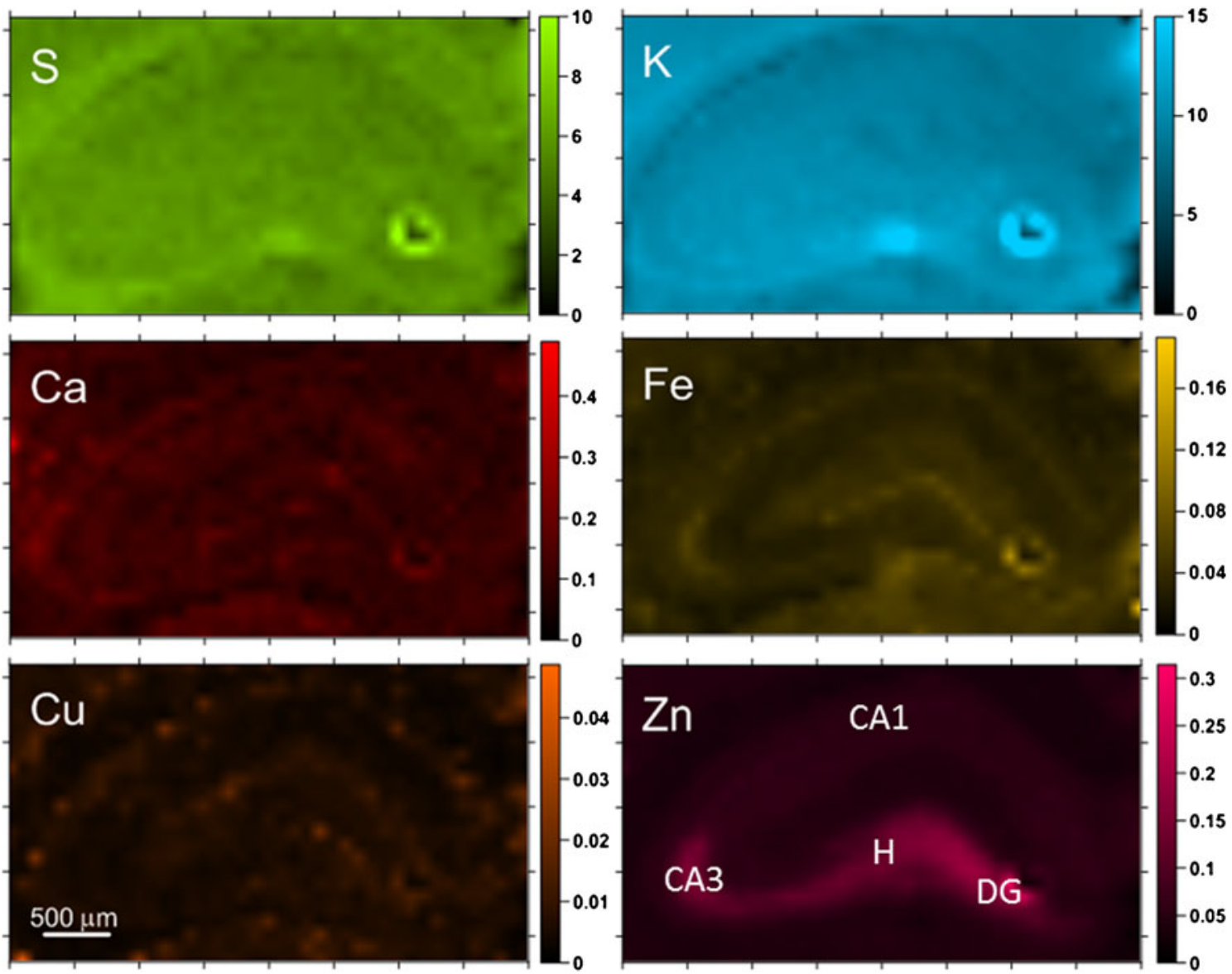

Fig. 3 Elemental maps obtained for hippocampal tissue from a selected control animal. Scales display masses per unit area of the elements in micrograms per square centimeter

in all the three mentioned areas exceeds the level of this element recorded for the control group.

Because of the high mortality rate in rats after pilocarpine injection, only one of examined animal groups was abundant enough to analyze the correlations between the elemental anomalies and quantitative parameters describing animal behavior in the acute phase of pilocarpine-induced status epilepticus. The correlative analysis was carried out for the most abundant SE7D group. The behavioral parameters recorded for epileptic animals included: latency time, meaning the time between pilocarpine administration and the first motor seizure sign; intensity of maximal seizures; and total time of seizure activity within the 6-h-long observation period.

The motor seizures intensity was rated on a 6-point scale with respect to the symptoms and their intensity. The scale was used in our previous study [32] and corresponds to that introduced by Racine [33] and widely used in studies on animal models of epilepsy.

1. Light seizures (rated as 0.5 or 1.0 )

For 0.5 -immobility, piloerection, salivation, eyes narrowing, face and vibrissae twitching, and ears rubbing with forepaws

For 1.0 - head nodding and chewing movements

2. Intermediate seizures (rated as 1.5 or 2.0)

For 1.5-clonic movements of forelimbs and mild whole body convulsions, exophthalmia, and aggressive behavior

For 2.0 - rearing and running with stronger tonicclonic motions including hind limbs, the tail, hypertension, and lockjaw

3. Heavy seizures (rated as 2.5 or 3.0)

For 2.5-rearing and falling and eye congestion

For 3.0-loss of postural tone with general body rigidity

The behavioral parameters recorded for the SE7D group are shown in Table 3. In turn, the results of the analysis of the dependencies between them and elemental anomalies measured using X-ray fluorescence microscopy are presented, as Spearman's rank correlation coefficients, in Table 4. The values statistically significant at the $95 \%$ confidence level are marked.

Spearman's rank correlation is a nonparametric alternative to correlation and is typically used when the data do not 
Mass per unit area of $S\left[\mu \mathrm{g} / \mathrm{cm}^{2}\right]$

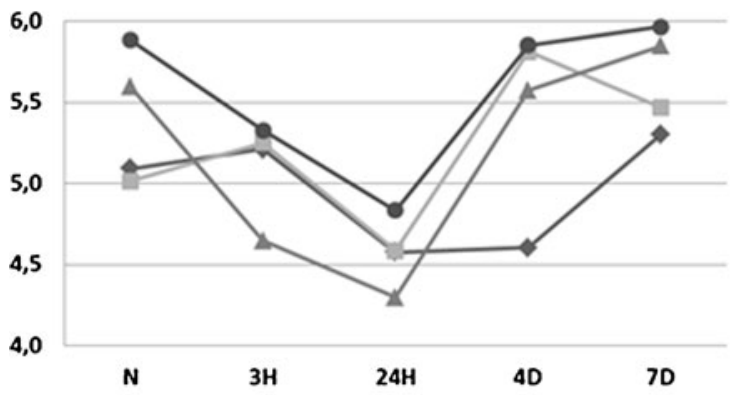

Mass per unit area of $\mathrm{Ca}\left[\mu \mathrm{g} / \mathrm{cm}^{2}\right]$

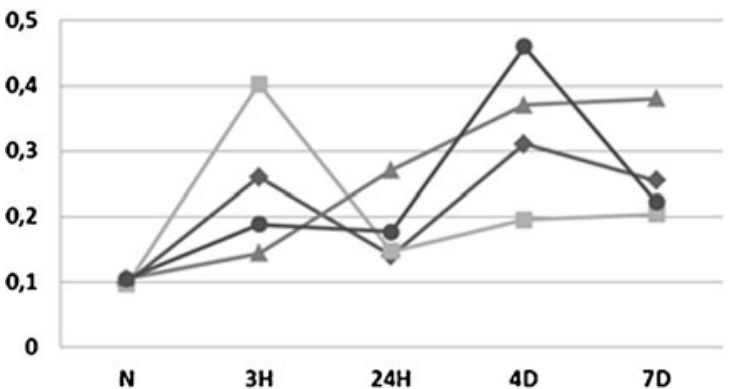

Mass per unit area of $\mathrm{Cu}\left[\mu \mathrm{g} / \mathrm{cm}^{2}\right]$

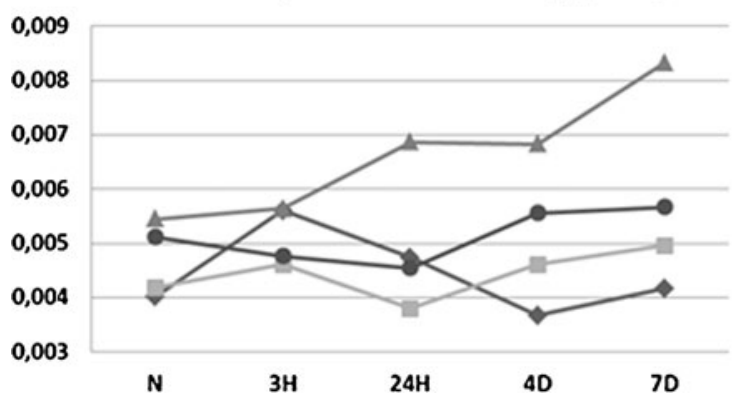

Mass per unit area of $\mathrm{K}\left[\mu \mathrm{g} / \mathrm{cm}^{2}\right]$
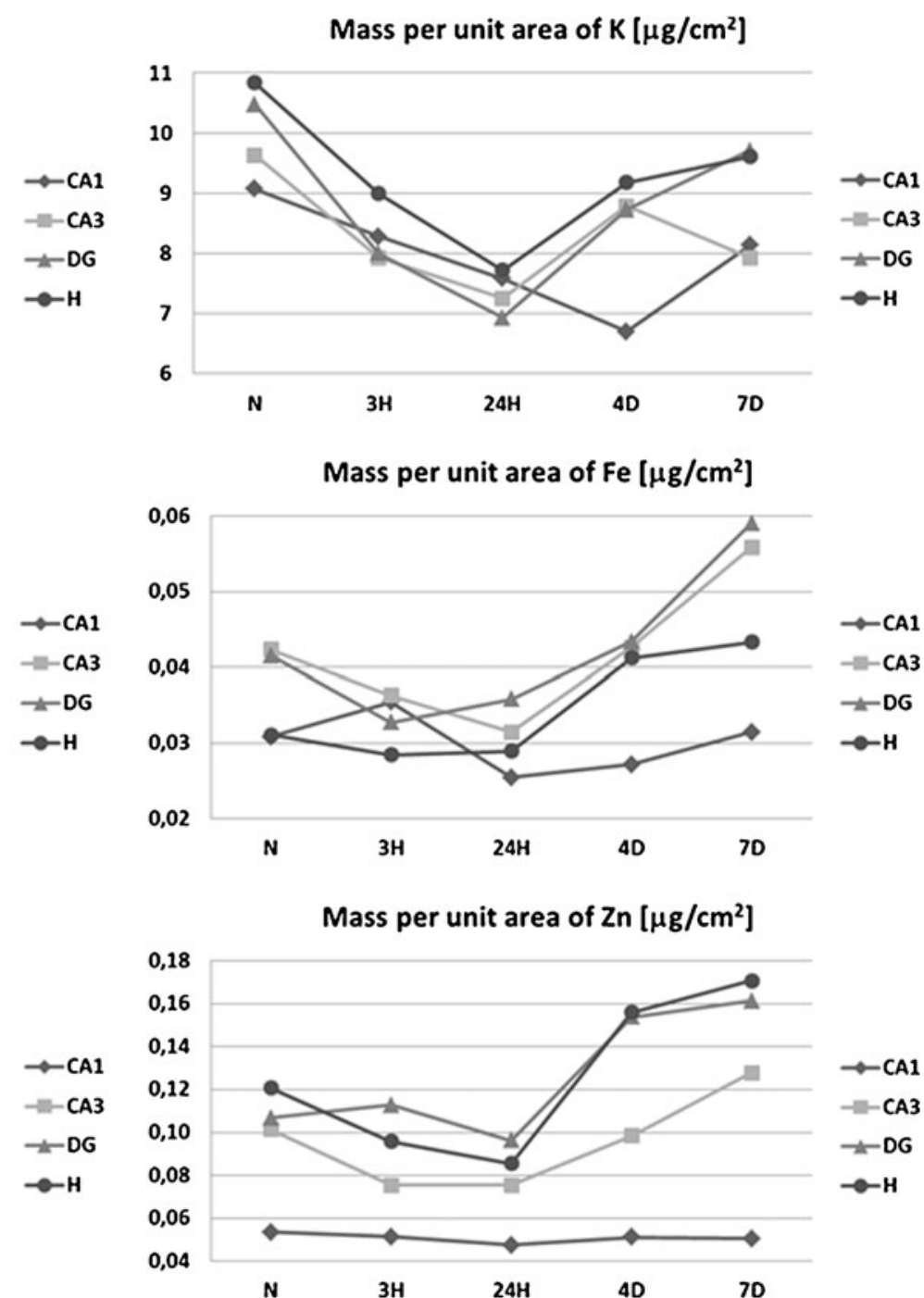

Mass per unit area of $\mathrm{Fe}\left[\mu \mathrm{g} / \mathrm{cm}^{2}\right]$

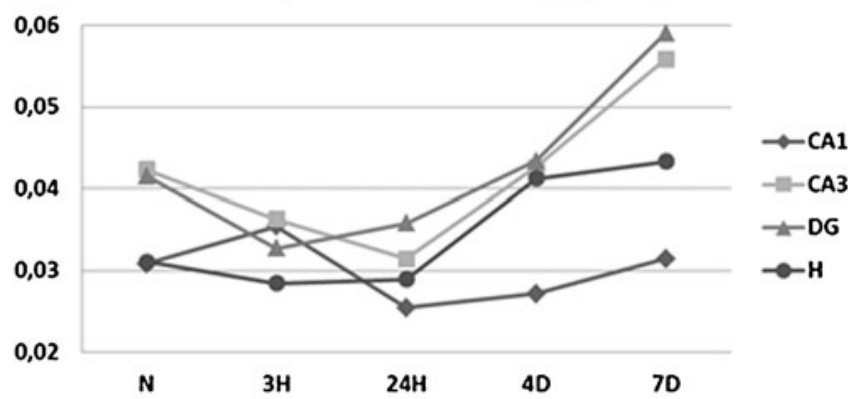

Mass per unit area of $\mathrm{Zn}\left[\mu \mathrm{g} / \mathrm{cm}^{2}\right]$

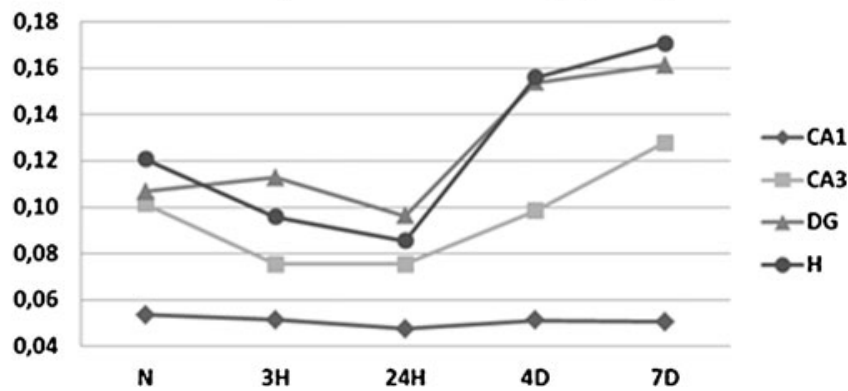

Fig. 4 Changes in median values of elemental areal densities for the analyzed hippocampal areas (CA1, CA3, DG, and H) in relation to the time after pilocarpine injection

meet the assumptions about normality, homoscedasticity, and linearity. It is a measure of statistical dependence between two variables which allows easily identifying the strength of correlation within a dataset of two variables. Because in our study we have not got enough data to test the normality and homoscedasticity assumptions of regression and correlation, we decided to use Spearman's rank correlation to test whether the selected elemental and behavioral parameters covary.

Based on the data from Table 4, one can conclude that 7 days after pilocarpine administration, the levels of selected elements still strongly depend on the progress of the acute phase of pilocarpine-induced status epilepticus. Such observations were done mainly for $\mathrm{Ca}$ and $\mathrm{K}$. Areal density of $\mathrm{Ca}$ in all analyzed areas was negatively correlated with the latency time and positively correlated with the total time of seizure activity within the observation period. For $\mathrm{K}$ and all examined hippocampal areas, the exactly opposite relations were observed. Additionally, for this element, negative correlation was noticed between CA1 and CA3 accumulation and intensity of maximal seizures.

The levels of $\mathrm{S}$ and $\mathrm{Cu}$ were the higher the later the seizure activity occurred after pilocarpine injection and negatively correlated with the intensity of maximal seizures. In turn, $\mathrm{Zn}$ areal density, similarly as it was found for $\mathrm{Ca}$, showed (in DG area) positive correlation with the total time of seizure activity.

\section{Discussion}

In the present paper, X-ray fluorescence microscopy was applied to follow the processes occurring in rat hippocampal formation during the period of epileptogenesis. In the study, 


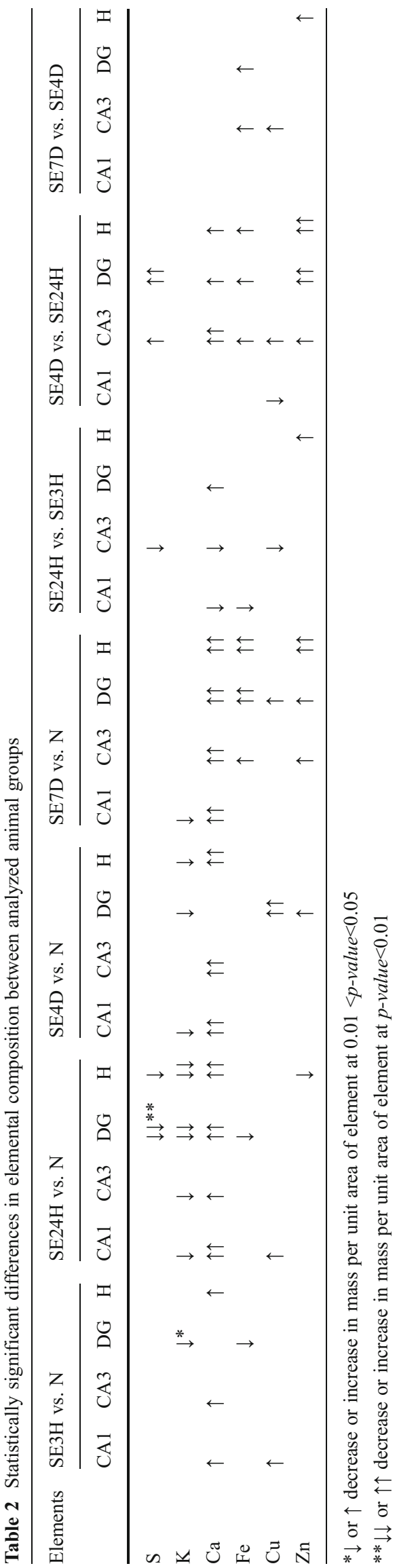

one of the status epilepticus animal models of epilepsy was used, namely the model of TLE with pilocarpine-induced seizures. In order to analyze the dynamics of seizureinduced elemental changes, samples taken from seizureexperiencing animals $3 \mathrm{~h}$ and 1,4 , and 7 days after proconvulsive agent administration were examined.

The detailed quantitative elemental analysis of CA1, CA3, DG, and H hippocampal areas and subsequent statistical evaluation showed that excitotoxicity, mossy fibers sprouting, and iron-induced oxidative stress are the processes which may be responsible for seizure-induced neurodegenerative changes and spontaneous seizure activity occurring in the chronic phase of the pilocarpine model. The detailed discussion confirming the thesis is presented below.

A significant decrease in the $\mathrm{S}$ content in CA3 hippocampal area detected in the present study $24 \mathrm{~h}$ following seizure induction might reflect effects of mitochondrial oxidative stress on cellular concentration of sulfurcontaining amino acids and their metabolism [34, 35]. A spectacular consequence of seizures is glutathione depletion (52.9 \% of the normal level) in the hippocampus as early as $1 \mathrm{~h}$ after limbic status epilepticus [36] considerably reducing endogenous antioxidant stores. A subsequent return of the $\mathrm{S}$ content to the normal level could be attributed to the onset of reactive processes leading to partial at least, functional recovery of the hippocampal tissue [37]. In this respect, long-term consequences of mitochondrial oxidative stress and their role in epileptogenesis need further exploration [38].

In all hippocampal areas, despite $\mathrm{DG}$, the $\mathrm{Ca}$ content increases significantly already $3 \mathrm{~h}$ after pilocarpine administration. In DG, this rise appears with a delay between the third and twenty-fourth hours, when in the other examined areas the level of $\mathrm{Ca}$ decreases (CA1 and $\mathrm{CA} 3$ ) or remains constant $(\mathrm{H})$. In the next time period, the areal density of $\mathrm{Ca}$ increases again in CA3, DG, and $\mathrm{H}$ hippocampal areas and remains at a constant level afterwards which is at least a factor of 2 higher for all analyzed areas than for the control group.

An increased $\mathrm{Ca}$ level in the acute phase of the pilocarpine model is a result of seizure-induced excessive glutamate release which activates postsynaptic NMDA receptors and triggers receptor-mediated $\mathrm{Ca}$ influx [38]. As it was shown in the "Results," this rise in CA1, CA3 and $\mathrm{H}$ hippocampal areas was observed for an earlier period than in DG. Such an observation confirms that DG granular cells present relatively high, comparing to CA1 and CA3 pyramidal cells as well as hilar neurons, resistance to seizureinduced excitotoxicity [25, 39].

Excessive accumulation of $\mathrm{Ca}$ in the acute period leads, in turn, to increased glutamate release, which acts on the AMPA/kainate receptors and thus allows further influx of $\mathrm{Na}^{+}$and $\mathrm{Ca}^{2+}$ ions into neurons. As a consequence of this 

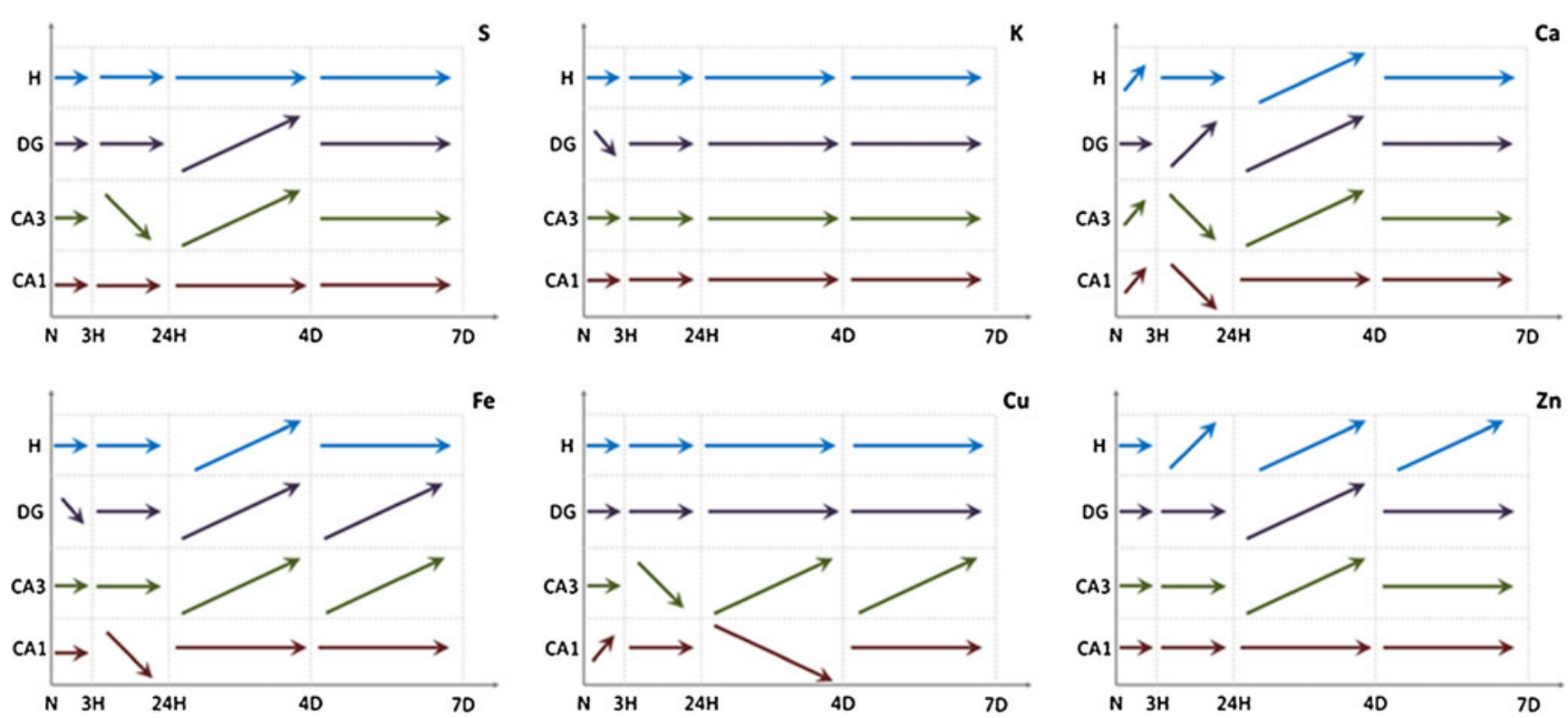

Fig. 5 Statistically significant changes in elemental accumulation between subsequent moments after pilocarpine injection

process, $\mathrm{Mg}^{2+}$ ions, which in the normal conditions block NMDA receptors, are removed. This allows further activation of these receptors through glutamate and $\mathrm{Ca}$ influx into postsynaptic cells [40] what we might observe as a secondary increase of the Ca level in CA3, DG, and H hippocampal areas in the latent phase (4 days after pilocarpine administration).

Table 3 The results of behavioral observations recorded for SE7D group

\begin{tabular}{lrlr}
\hline Sample code & TL (min) & MAX & T (min) \\
\hline NS070 & 360 & 0 & 0 \\
NS071 & 30 & 3 & 220 \\
NS072 & 300 & 0.5 & 80 \\
NS074 & 360 & 0 & 0 \\
NS075 & 20 & 2.5 & 340 \\
NS076 & 60 & 1 & 310 \\
NS079 & 30 & 1.5 & 340 \\
NS0710 & 30 & 2.5 & 310 \\
NS0711 & 30 & 1.5 & 320 \\
NS0712 & 80 & 0.5 & 10 \\
NS0713 & 360 & 0 & 0 \\
NS0714 & 20 & 2.5 & 330 \\
NS0716 & 60 & 3 & 10 \\
NS0717 & 360 & 0.5 & 20 \\
NS0718 & 30 & 0 & 0 \\
NS0719 & 1.5 & 340 \\
\hline
\end{tabular}

$T L$ latency time, meaning the time between pilocarpine administration and the first motor seizure sign, $M A X$ intensity of maximal seizures, $T$ total time of seizure activity within the 6-h-long observation period
An increase in $\mathrm{Ca}^{2+}$ signal was previously recorded in epileptic brain slices and localized in astrocytes [41, 42]. It is necessary to mention that seizures themselves could evoke proliferation of the astroglial cells [43, 44] further reinforcing the total elevation in $\mathrm{Ca}$ tissue contents lasting even three postseizure days.

As it was shown in the "Results," the Fe areal density decreased in the acute and increased in the latent phase after pilocarpine administration. Seven days after SE injection, its levels in $\mathrm{CA} 3, \mathrm{DG}$, and $\mathrm{H}$ are higher than those measured for the control group. The decrease of the Fe areal density during the acute period of pilocarpine-induced SE is probably an effect of seizures-related reversible blood-brain barrier injury [45-48]. In turn, the increased level of Fe observed for the latent phase indicates that this element may play an important role in the processes leading to seizure-induced neurodegenerative changes of the hippocampal formation and pathogenesis of spontaneous seizures in the chronic phase of pilocarpine model. Iron, promoting the production of free radicals, potentiates the effect of oxidative stress. As a transitive metal it catalyzes Fenton's reaction leading to the creation of highly reactive hydroxyl radicals. Clinical studies show that brain injuries, occurring with extravasation of red blood cells, hemolysis, and the deposition of iron compounds, often result with the appearance of posttraumatic seizures [49]. Similar effects are obtained experimentally by injection of iron salts or hem in particular brain areas $[50,51]$. In both cases, the appearance of epileptic seizures is connected with increased, through accumulating iron, production of free radicals and occurring as a result of their action lipid peroxidation $[50,52,53]$. 
Table 4 The Spearman's rank correlation coefficients obtained at the confidence level of $95 \%$ time between pilocarpine administration and the first motor seizure sign, $M A X$ intensity of maximal seizures, $T$ total time of seizure activity within the 6-hlong observation period.

Statistically significant correlations coefficients are in bold

\begin{tabular}{|c|c|c|c|c|c|c|c|}
\hline Area & Parameter & $\mathrm{S}$ & K & $\mathrm{Ca}$ & $\mathrm{Fe}$ & $\mathrm{Cu}$ & $\mathrm{Zn}$ \\
\hline \multirow[t]{3}{*}{ CA1 } & $\mathrm{TL}$ & 0.54 & 0.71 & -0.50 & 0.27 & 0.51 & 0.43 \\
\hline & MAX & -0.67 & -0.64 & 0.29 & -0.47 & -0.50 & -0.31 \\
\hline & $\mathrm{T}$ & -0.30 & -0.63 & 0.73 & -0.18 & -0.38 & -0.46 \\
\hline \multirow[t]{3}{*}{ CA3 } & $\mathrm{TL}$ & 0.30 & 0.64 & -0.55 & -0.13 & 0.26 & -0.06 \\
\hline & MAX & -0.38 & -0.51 & 0.35 & -0.16 & -0.37 & -0.19 \\
\hline & $\mathrm{T}$ & -0.15 & -0.62 & 0.71 & 0.31 & -0.26 & 0.32 \\
\hline \multirow[t]{3}{*}{ DG } & $\mathrm{TL}$ & -0.10 & 0.53 & -0.53 & -0.38 & -0.11 & -0.30 \\
\hline & MAX & 0.06 & -0.26 & 0.30 & 0.29 & 0.14 & 0.19 \\
\hline & $\mathrm{T}$ & 0.30 & -0.49 & 0.74 & 0.49 & 0.15 & 0.50 \\
\hline \multirow[t]{3}{*}{$\mathrm{H}$} & $\mathrm{TL}$ & -0.21 & 0.62 & -0.58 & -0.24 & 0.08 & -0.23 \\
\hline & MAX & 0.17 & -0.37 & 0.45 & 0.22 & 0.10 & 0.22 \\
\hline & $\mathrm{T}$ & 0.37 & -0.70 & 0.62 & 0.12 & -0.11 & 0.22 \\
\hline
\end{tabular}

Seven days after pilocarpine administration, a significant increase of $\mathrm{Zn}$ accumulation was observed in CA3, DG, and $\mathrm{H}$ hippocampal areas but not in CA1 region. An increased areal density of $\mathrm{Zn}$ in the latent phase is probably a consequence of mossy fibers sprouting which means synaptic reorganization occurring in the inner molecular layer of DG. In the normal conditions, mossy fibers, being the axons of DG granule cells, target to pyramidal cells of CA3 region. However, after epileptic injury they sprout into the inner molecular layer and hilus, as well as stratum oriens in CA3 [54] and may give significant input in the hyperexcitability and epileptic seizures occurring both in humans and in animal models of the disease [55-59]. Because large terminals of mossy fibers of dentate granule cells contain the highest amounts of $\mathrm{Zn}$ in the brain [60], the new collaterals sprouted in the molecular layer are probably responsible for the higher content of this element, which is observed in epileptic animals from the latent phase.

Ongoing seizures may also trigger $\mathrm{Zn}^{2+}$ release both from synaptic terminals [61-63] and from intracellular stores [64, 65]. However, for none of the analyzed hippocampal areas, we observed an excessive accumulation of $\mathrm{Zn}$ in the acute phase of pilocarpine-induced status epilepticus (SE3H and SE24H groups). Twenty-four hours after pilocarpine administration, the level of $\mathrm{Zn}$ in the hillus of DG was even lower than the level found for naive control animals. Therefore, the phenomena of mossy fibers sprouting seems to be much better explanation for an increase in $\mathrm{Zn}$ areal density occurring in DG, $\mathrm{H}$, and $\mathrm{CA} 3$ hippocampal areas 7 days after seizure induction.

Besides the dynamics of seizure-induced elemental changes in the hippocampal formation, the correlations between elemental anomalies and quantitative parameters describing animal seizure behavior in the acute period were examined. The statistical analysis based on Spearman's rank correlation coefficients was carried out for the most abundant SE7D group. The obtained results showed at the significance level of 0.05 that the areal densities of selected elements measured in the latent period strongly depend on the progress of the acute phase of pilocarpine-induced status epilepticus. Especially important seem to be the recorded changes in $\mathrm{Ca}$ and $\mathrm{Zn}$ levels which suggest that the intensity of the processes such as excitotoxicity and mossy fibers sprouting depend on the total time of seizure activity. These results as well as further relations found between the levels of $\mathrm{S}, \mathrm{K}$, and $\mathrm{Cu}$ and the intensity of seizures clearly confirm how important it is to control the duration and intensity of seizures in clinical practice.

\section{Conclusions}

The results presented in this paper confirmed the utility of $\mathrm{X}$-ray fluorescence microscopy in investigations of mechanisms involved in the pathogenesis and progress of epilepsy. The topographic and quantitative elemental analysis of the hippocampal formations at different stages of epileptogenesis showed that excitotoxicity, mossy fibers sprouting, and iron-induced oxidative stress may be the processes underlying seizure-induced neurodegenerative changes and spontaneous seizure activity occurring in the chronic phase of pilocarpine model.

Acknowledgments This work was partially supported by the Polish Ministry of Science and Higher Education and its grants for scientific research IUVENTUS PLUS No. JP2010005370 and for the statutory research of the Institute of Zoology (Jagiellonian University) K/ZDS/ 002594. The research leading to these results has received funding from the European Community's Seventh Framework Programme (FP7/2007-2013) under grant agreement No. 312284 and was realized in frame of experimental grants: I-20110056 EC (DESY) and BIO-1 (ANKA). The authors wish to express their appreciation to Prof. Henryk Figiel for valuable discussions and comments in the preparation of the manuscript. 
Open Access This article is distributed under the terms of the Creative Commons Attribution License which permits any use, distribution, and reproduction in any medium, provided the original author(s) and the source are credited.

\section{References}

1. Koningsberger DC, Prins R (eds) (1988) X-ray absorption, principles, Applications, techniques of EXAFS, SEXAFS and XANES. Wiley, New York

2. Bordovitsyn VA, Ternow IM (eds) (1999) Synchrotron radiation theory and its development. World Scientific Publishing Company, Singapore

3. Snigireva I, Snigirev A (2006) J Env Monit 8:33-42

4. Bilderback DH, Hoffman SA, Thiel DJ (1994) Science 263:201-203

5. Lengeler B, Schroer C, Tummler J, Benner B, Richwin M, Snigirev A, Snigireva I, Drakopulos M (1999) J Synchr Rad 6:1153-1167

6. Hignette O, Cloetens P, Rostaing G, Bernard P, Morawe C (2005) Rev Sci Instr 76:1-5

7. Sorensen TL, McAuley KE, Flaig R, Duke EM (2006) Trends Biotechnol 24:500-508

8. Spitale RC, Wedekind JE (2009) Methods 49:87-100

9. Chwiej J, Adamek D, Szczerbowska-Boruchowska M, Krygowska-Wajs A, Wojcik S, Falkenberg G, Manka A, Lankosz M (2007) J Biol Inorg Chem 12:204-211

10. Chwiej J, Sarapata A, Janeczko K, Stegowski Z, Appel K, Setkowicz Z (2011) J Biol Inorg Chem 16:275-283

11. Ducić T, Quintes S, Nave KA, Susini J, Rak M, Tucoulou R, Alevra M, Guttmann P, Salditt T (2011) J Struct Biol 173:202-212

12. Szczerbowska-Boruchowska M, Lankosz M, Czyzycki M, Adamek D (2011) Anal Chim Acta 699:153-160

13. Miller LM, Dumas P (2010) Curr Opin Struct Biol 20:649-656

14. Petibois C, Piccinini M, Guidi MC, Marcelli A (2010) Synchrotron Radiat 17:1-11

15. Adams F, Janssens K, Snigirev A (1998) J Anal Atom Spectr $13: 319-331$

16. Janssens KH, Rindby A, Adams F (2000) Microscopic x-ray fluorescence analysis. Wiley, Chichester

17. Snigireva I, Snigirev A (2006) J Environ Monit 8:33-42

18. Breydo L, Uversky VN (2011) Metallomics 3:1163-1180

19. Perry G, Sayre LM, Atwood CS, Castellani RJ, Cash AD, Rottkamp CA, Smith MA (2002) CNS Drugs 16:339-352

20. Gaeta A, Hider RC (2005) Br J Pharmacol 146:1041-1059

21. Rivera-Mancía S, Pérez-Neri I, Ríos C, Tristán-López L, RiveraEspinosa L, Montes S (2010) Chem Biol Interact 186:184-199

22. Delorenzo RJ, Sun DA, Deshpande LS (2005) Pharmacol Ther 105:229-266

23. Loscher W (2002) Epilepsy Res 50:105-123

24. Sharma AK, Reams RY, Jordan WH, Miller MA, Thacker HL, Snyder PW (2007) Toxicol Path 35:984-999

25. Chang BS, Lowenstein DH (2003) N Engl J Med 349:1257-1266

26. Babb TL (1999) Adv Neurol 79:763-779

27. Engel J (1993) Curr Opin Neurol Neurosurg 6:240-249

28. Curia G, Longo D, Biagini G, Jones RSG, Avoli M (2008) J Neurosci Meth 172:143-157

29. Scorza FA, Arida RM, Da Graca Naffah-Mazzacoratti M, Scerni DA, Calderazzo L, Cavalheiro EA (2009) An Acad Bras Cienc 81:345-365
30. Paxinos G, Watson C (1989) The rat brain in stereotaxic coordinates. Academic Press, Australia

31. Chwiej J, Winiarski W, Ciarach M, Janeczko K, Lankosz M, Janeczko K, Rickers K, Setkowicz Z (2008) J Biol Inorg Chem 13:1267-1274

32. Setkowicz Z, Janeczko K (2003) Epilepsy Res 53:216-224

33. Racine RJ (1972) Electroencephalogr Clin Neurophysiol 32:281-294

34. Lin Y, Han Y, Xu J, Cao L, Gao J, Xie N, Zhao X, Jiang H, Chi Z (2010) Cell Mol Neurobiol 30:947-954

35. Sabens Liedhegner EA, Gao XH, Mieyal JJ (2012) Antioxid Redox Signal 16:543-566

36. de Freitas RM, do Nascimento KG, Ferreira PM, Jordán J (2010) Pharmacol Biochem Behav 94:341-345

37. Gorter JA, Van Vliet EA, Rauwerda H, Breit T, Stad R, van Schaik L, Vreugdenhil E, Redeker S, Hendriksen E, Aronica E, Lopes da Silva FH, Wadman WJ (2007) Epilepsia 48:53-64

38. Fujikawa DG (2005) Epilepsy Behav 7:3-11

39. Badawy RA, Harvey AS, Macdonell RA (2009) J Clin Neurosci 16:485-500

40. Scorza FA, Arida RM, Naffah-Mazzacoratti Mda G, Scerni DA, Calderazzo L, Cavalheiro EA (2009) An Acad Bras Cienc 81:345-365

41. Tian GF, Azmi H, Takano T, Xu Q, Peng W, Lin J, Oberheim N, Lou N, Wang X, Zielke HR, Kang J, Nedergaard M (2005) Nat Med 11:973-981

42. Fellin T, Gomez-Gonzalo M, Gobbo S, Carmignoto G, Haydon PG (2006) J Neurosci 26:9312-9322

43. Fonseca CG, Green CR, Nicholson LF (2002) Brain Res 929:105-116

44. Garzillo CL, Mello LE (2002) Epilepsia 43:107-109

45. Ates N, Esen N, Ilbay G (1999) Pharmacol Res 39:305-310

46. Ziylan YZ, Lefauconnier JM, Ates N, Bernard G, Bourre JM (1992) Mech Ageing Dev 62:319-327

47. Ziylan YZ, Ates N (1989) Neurosci Lett 96:179-184

48. Fisher RS (1989) Brain Res Brain Res Rev 14:245-278

49. Payan H, Toga M, Bérard-Badier M (1970) Epilepsia 11:81-94

50. Willmore LJ, Sypert GW, Munson JB (1978) Ann Neurol 4:329-436

51. Golden N, Darmadipura S, Bagiada NA (2010) Singapore Med 51:105-109

52. Willmore LJ, Rubin JJ (1982) Brain Res 246:113-119

53. Triggs WJ, Willmore LJ (1984) J Neurochem 42:976-980

54. Scharfman HE (2007) Prog Brain Res 163:627-637

55. Masukawa LM, O'Connor WM, Burdette LJ, McGonigle P, Sperling MR, O'Connor MJ, Uruno K (1997) Adv Neurol 72:53-68

56. Isokawa M, Mello LE (1991) Neurosci Lett 129:69-73

57. Wuarin JP, Dudek FE (1996) J Neurosci 16:4438-4448

58. Lynch M, Sutula T (2000) J Neurophysiol 83:693-704

59. Dudek FE, Sutula TP (2007) Prog Brain Res 163:755-773

60. Frederickson CJ, Suh SW, Silva D, Frederickson CJ, Thompson RB (2000) J Nutr 130:1471-1483

61. Vogt K, Mellor J, Tong G, Nicoll R (2000) Neuron 26:187-196

62. Lin DD, Cohen AS, Coulter DA (2001) J Neurophysiol 85:11851196

63. Molnar P, Nadler JV (2001) Brain Res 910:205-207

64. Aizenman E, Stout AK, Hartnett KA, Dineley KE, Mclaughlin B, Reynolds IJ (2000) J Neurochem 75:1878-1888

65. Bossy-Wetzel E, Talantova MV, Lee WD, Scholzke MN, Harrop A, Mathews E, Gotz T, Han J, Ellisman MH, Perkins GA, Lipton SA (2004) Neuron 41:351-365 